Arch Virol (1993) [Suppl] 7: 135-151

(C) Springer-Verlag 1993

\title{
Pathogenesis of Borna disease
}

\author{
L. Stitz ${ }^{1}$, T. Bilzer ${ }^{2}$, J.A. Richt ${ }^{1}$, and R. Rott $^{1}$ \\ ${ }^{1}$ Institut für Virologie, Justus-Liebig-Universität, Gießen \\ ${ }^{2}$ Abteilung für Neuropathologie, Heinrich-Heine-Universität, Düsseldorf, \\ Federal Republic of Germany
}

Summary. Borna disease represents a unique model of a virus-induced immunological disease of the brain. Naturally occurring in horses and sheep, the mechanisms of pathogenesis have been studied in experimental animals, namely in the rat. Many investigations have revealed that the infection of the natural hosts principally follows the same pathogenic pathways as observed in rats, leading to a severe encephalomyelitis. This affliction of the central nervous system results in severe neurological disorders that again, are fully comparable in laboratory animals to those in the natural and the different experimental hosts. In addition, alterations have been reported which are also based on the infection of the brain and do not result in the classical encephalitic clinical picture but rather in alterations of behavior. However, to all of our knowledge, the various clinical pictures of Borna disease are not caused by the infecting virus itself but rather by the hosts immune response towards it, i.e. by a virus-induced cell-mediated immunopathological reaction. The importance of virus-specific $\mathrm{CD} 4+\mathrm{T}$ cells as exemplified by a cultured $\mathrm{T}$ cell line and of CD8+ T cells as shown by immunomodulatory substances and specific antibody treatment in vivo for the pathogenesis of acute Borna disease will be elucidated here. In addition, evidence will be provided that virus-specific $\mathrm{CD} 8+\mathrm{T}$ cells are also responsible for the dramatic brain atrophy in the chronic phase of the disease in rats. Therefore, Borna disease not only lends itself exquisitely well to the study of the pathogenesis of an immunopathological disease of the brain but also represents one of the few models for immune-mediated tissue destruction that eventually leads to brain atrophy and clinically to dementia.

\section{Introduction}

Afflictions of the central nervous system have not only been in the focus of scientific research since most recently, when pathological alteration 
caused by viruses or virus-like agents have attained public interest. Most prominently, the presence of HIV-1 antigen in the brains of human patients suffering from dementia [26] and the most recent appearance of "mad-cow disease" caused by the yet unidentified "Scrapie agent" might be mentioned. Many autoimmune and virus-induced immunopathological alterations of the brain have been studied in experimental animals and serve as models for animal and human diseases. In the classical example, infection of mice with the lymphocytic choriomeningitis virus and recently also in Theiler virus infection in mice, the presence and the pathogenic importance of a virus-specific immune response, especially mediated by $\mathrm{T}$ cells, has been demonstrated in the brain $[6,10]$. Other models studied in rodents include corona virus and measles virus infections in rats where an autoimmune reaction is of crucial importance in the pathogenesis of virus-induced diseases of the brain [19]. In addition to HIV in AIDS encephalopathy, several observations in human patients support this view, namely the detection of measles virus in cases of subacute sclerosing panencephalopathy [33], and of papovavirus in progressive multifocal leukoencephalopathy [22, 41]. Furthermore, several viruses have been suggested to be involved in the development of multiple sclerosis [18].

In general, the outcome of a viral infection depends on characteristics of the virus and the efficiency and speed of the immune system including natural defense mechanisms to react to the invading agent. Viruses that cause cytopathogenicity are a much greater threat to the host than viruses that are non-cytopathic. Consequently, the evolution of the immune system has been significantly influenced by the demand for an efficient and rapid elimination of cytolytic viruses to avoid widespread infection and reduce tissue destruction. However, this strategy of a highly efficient immune reaction bears a considerable disadvantage for the host in the case of infection with persistent viruses lacking cytopathogenicity, since the immune system is apparently not capable of distinguishing between cytolytic and non-cytolytic viruses. The result may be damage to the host by an immune reaction although the agent that induced the immune response is otherwise perfectly innocuous.

\section{Borna disease and Borna disease virus}

An example of such a non-cytolytic virus is Borna disease virus. The virus and, respectively, the disease has been named after the town of Borna in Saxony, where in 1895 an endemic among horses of a cavalry regiment resulted in the loss of a high number of animals. By that time, the disease had already been recognized for about 100 years but 
was known under various synonyms reflecting central nervous system disorders. A particular characteristic of the disease is the variably long incubation period that was the reason why BD has been grouped with "slow" virus infections. The disease is associated with disturbances of motility and in sensory functions and usually results in paralysis and death in affected natural hosts [reviewed in 16]. Pathohistologically, BD is classified as a progressive polioencephalomyelitis with pronounced inflammatory reactions in the basal cortex, the nucleus caudatus and the entire hippocampal area.

BD virus has been only recently characterized as an RNA virus [7, $15,17,30,39]$ with strong evidence for negative-sense polarity [3, 7]. The virus which is tightly cell associated and apparently lacks cytopathogenicity in vitro and in vivo replicates preferentially in cells derived from the neural crest [12]. However, after cocultivation [12] or after repeated infection with virus-containing supernatants from the brain of infected rats, other cell types such as cultured astrocytes [27, 28] and skin cells [25] also can be directly infected in vitro.

After experimental infection, a wide variety of animals can be infected including species phylogenetically distant, such as birds and non-human primates. Recently, BDV-specific antibodies have also been detected in humans, indicating a possible role of $\mathrm{BDV}$ as a human pathogen [reviewed in 31].

The species that has been studied most intensively is the rat and most if not all progress in understanding the pathogenesis of this virus-induced disease of the central nervous systems was achieved by using this experimental animal.

After i.c. or i.n. infection of adult rats infectious virus and virusspecific antigen can be detected in high concentrations (Table 1) in the

Table 1. Consequence of BDV infection in adult rats

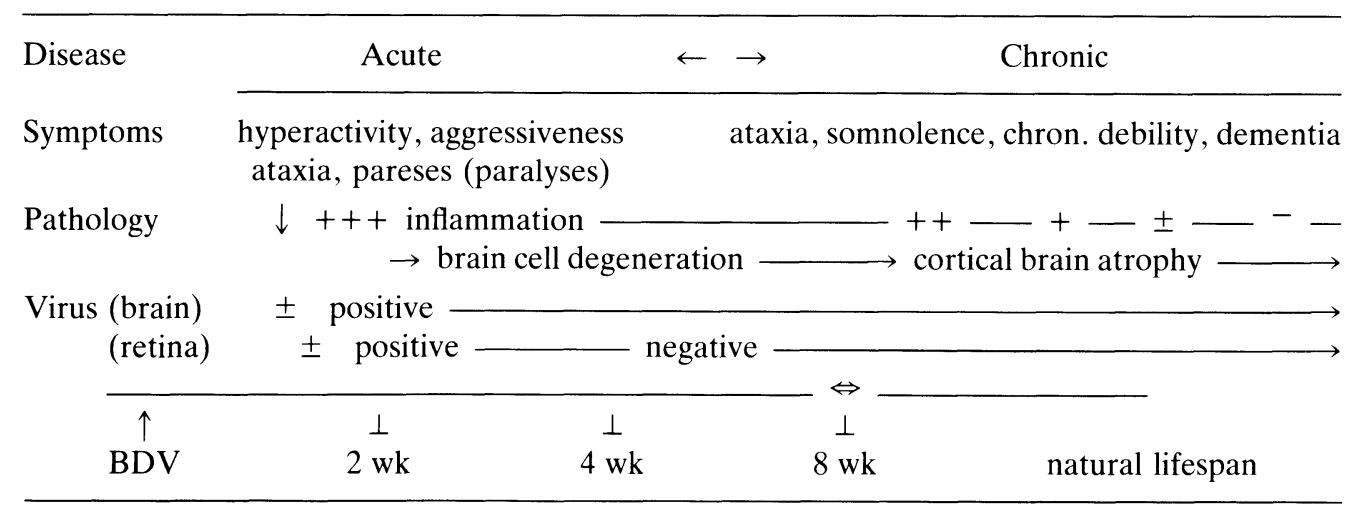


brain, the retina, the cerebrospinal fluid, in peripheral nerves and in the adrenal gland $[1,4,5,8,20,21,36]$. At later stages of the infection the virus disappears from the retina, but a persistent productive infection is maintained in the other tissues mentioned above. In parallel to the loss of virus from the eye, the animals go blind. In immunocompetent infected rats, disease symptoms such as lack of grooming, ataxia, hyperactivity and aggressiveness can be seen at about day 14 (Table 1). This acute phase of the disease lasts for about 3 weeks and later results in apathy, somnolence, progressive ataxia and paresis and sometimes results in paralysis and death. The clinical symptoms are paralleled by the development of an inflammatory reaction in the brain that is localized mainly perivascularly (Fig. 1). However, encephalitic lesions are also found in the brain parenchyma. In general, the inflammation is initially centered in the limbic system but spreads to other areas of the brain during infection $[8,20]$. The chronic phase of $\mathrm{BD}$ is clinically governed by increasing apathy and the rats remain in a severe somnolence, show signs of dementia and behavioral abnormalities [9, 21]. Some rats, however, develop an impressive obesity with body weights of up to $500-$ $600 \mathrm{~g}$ without clinical disease as compared to $200 \mathrm{~g}$ of uninfected adult rats. The histopathological picture of the chronic disease, which can be diagnosed after day 60 , is characterized by a significant decrease of the inflammatory reaction and the development of a severe hydrocephalus internus.

\section{Immunopathogenesis of Borna disease}

Significantly different pictures are seen in rats that show natural or druginduced immunoincompetence. Newborn, athymic, cyclophosphamide or cyclosporine A treated rats do not show Borna disease or the acute inflammatory reaction (Table 2). However, virus-specific nucleic acid and infectious virus, in addition to virus-specific antigen, is found in these animals in amounts comparable to fully immunocompetent rats [4, $13,20,25,36,37]$. Most strikingly, immunocompromised rats show no destruction of the retina, although the virus persists in the eye, i.e. the rats do not become blind despite the presence of virus in retinal layers (Table 2) [20]. This fact shows perfectly well that BDV has very low or even no direct cytopathogenicity in vivo. The importance of the immune response for the pathogenesis was further stressed by showing that adoptive transfer of lymphocytes from BDV-immune rats into immunoincompetent animals resulted in full-blown BD [20,37]. As a whole, these facts together demonstrate that $\mathrm{BD}$ is based on a virus-induced immunopathological reaction rather than on a direct virus-cell inter- 
Table 2. Consequence of BDV infection in newborn, athymic or immunosuppressed rats

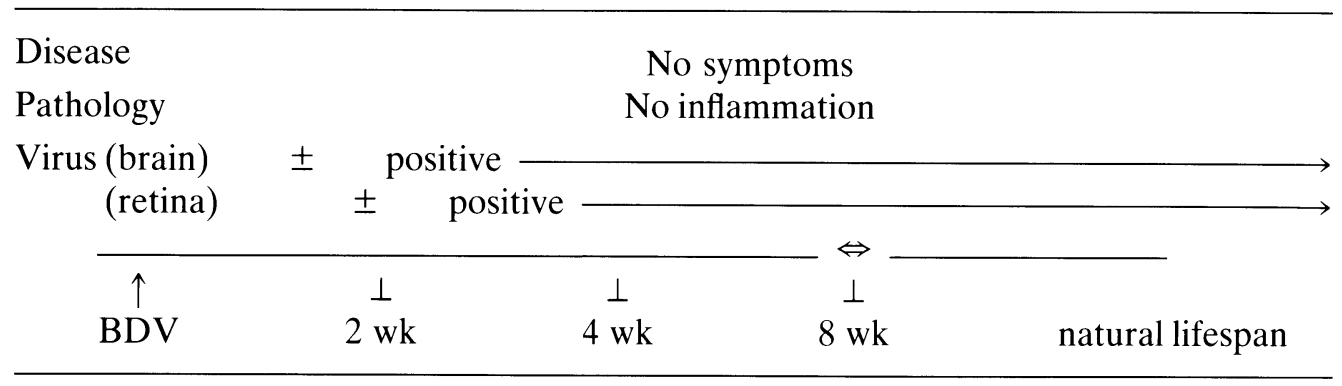

Table 3. Inhibition of BD after long treatment with CSA

\begin{tabular}{llcccc}
\hline $\begin{array}{l}\text { Wk after CSA } \\
\text { treatment }\end{array}$ & & \multicolumn{4}{c}{ Duration of CSA treatment } \\
\hline 5 & & - & 2 & 3 & 4 \\
\hline & disease & + & + & + & - \\
& encephalitic lesions & +++ & +++ & $+/++$ & - \\
20 & antibodies & 2,560 & $<40$ & $<40$ & $<40$ \\
& disease & + & + & + & - \\
& encephalitic lesions & + & + & + & - \\
60 & antibodies & 5,120 & 5,120 & $<40$ & $<40$ \\
& disease & + & & & - \\
& encephalitic lesions & $+/-$ & ND & ND & - \\
& antibodies & 5120 & & & $<40$
\end{tabular}

Rats were treated with CSA doses of $25 \mathrm{mg} / \mathrm{kg} /$ day given s.c. starting one day before infection for various time intervals; antibody titers are expressed as the reciprocal of end-point dilution

action. The possibility that antiviral antibodies play a significant role in the pathogenesis of $\mathrm{BD}$ can be excluded according to a variety of experimental evidence $[13,20]$. The most decisive argument against the involvement of antibodies in the pathogenesis of $\mathrm{BD}$ comes from experiments with the immunosuppressive drug cyclosporine A. Rats treated with CSA at appropriate doses and for a sufficiently long time can be protected from BD and do not mount an antibody response (Table 3) [37]. However, suboptimal treatment of BDV infected rats with CSA results in the development of an encephalitis in the absence of an anti-BDV antibody response (Table 3). Although these findings clearly indicated that the pathogenesis of $\mathrm{BD}$ is closely related to the cellular immune response, they did not reveal the cellular basis of the immunopathological process resulting in inflammation of the brain. By characterizing the cells present in the inflammatory lesions, employing 
Table 4. Adoptive transfer of a BDV-specific CD4+ $\mathrm{T}$ cell line into BDV-infected immunosuppressed rats

\begin{tabular}{ccccc}
\hline BDV infection & Immunosuppression & T cell transfer & Disease $^{\mathrm{a}}$ & Encephalitis $^{\mathrm{a}}$ \\
+ & - & - & $3 / 3$ & $3 / 3$ \\
\hline+ & + & - & $0 / 3$ & $0 / 3$ \\
\hline+ & + & + & $8 / 8$ & $8 / 8$ \\
\hline- & + & + & $0 / 3$ & $0 / 3$ \\
\hline
\end{tabular}

BDV-specific $\mathrm{T}$ cells were passively transferred i.v. immediately after in vitro restimulation at concentrations of $1 \times 10^{6}$ to $8 \times 10^{6}$. Recipients were immunosuppressed 1 day after i.c. infection by intraperitoneal injection of a single dose of $150 \mathrm{mg} / \mathrm{kg}$ cyclophosphamide.

${ }^{a}$ Number of rats per experimental group

immunohistochemical methods, a useful approach was found to solve this question. Immunohistological investigations into the quality of cells involved in the perivascular inflammatory reaction revealed the presence of $\mathrm{CD} 4+$ and $\mathrm{CD} 8+\mathrm{T}$ cells in addition to numerous macrophages and $\mathrm{B}$ cells (Fig. 1) [8]. To elucidate the importance of $\mathrm{T}$ cell subsets in the pathogenesis of BD in a first approach, a homogeneous virus-specific $\mathrm{T}$ cell line was established. Lymphocytes obtained from regional lymph nodes after subcutaneous immunization with purified virus-specific antigen were cultured and restimulated in vitro employing a protocol for the cultivation of CD4 + T cells [29]. Analysis of this cell line revealed BDVspecificity, MHC class II restriction and the phenotypical markers of CD4+ helper/inflammatory cells. Adoptive transfer of this cell line into BDV-infected immunosuppressed healthy recipients resulted in severe disease and death as early as day 5 after the injection of effector cells (Table 4) [28, 29]. In contrast, passive transfer into uninfected rats did not result in encephalitis or disease, which shows that this BDV-specific $\mathrm{T}$ cell line by itself is not encephalitogenic. These results, together with the immunohistological characterization of inflammatory cells in the brain of BDV-infected rats, strongly suggest that $\mathrm{BD}$ is caused by a delayed type hypersensitivity reaction (DTH). The finding of the importance of MHC class II restricted T cells agrees with the presence of MHC class II antigen in the brain of BDV-infected rats. This self antigen is detected on various cell types upon immunohistological characterization, namely perivascularly but also on oligodendrocytes, microglial and ependymal cells (Fig. 2) [8, 29, 35]. 

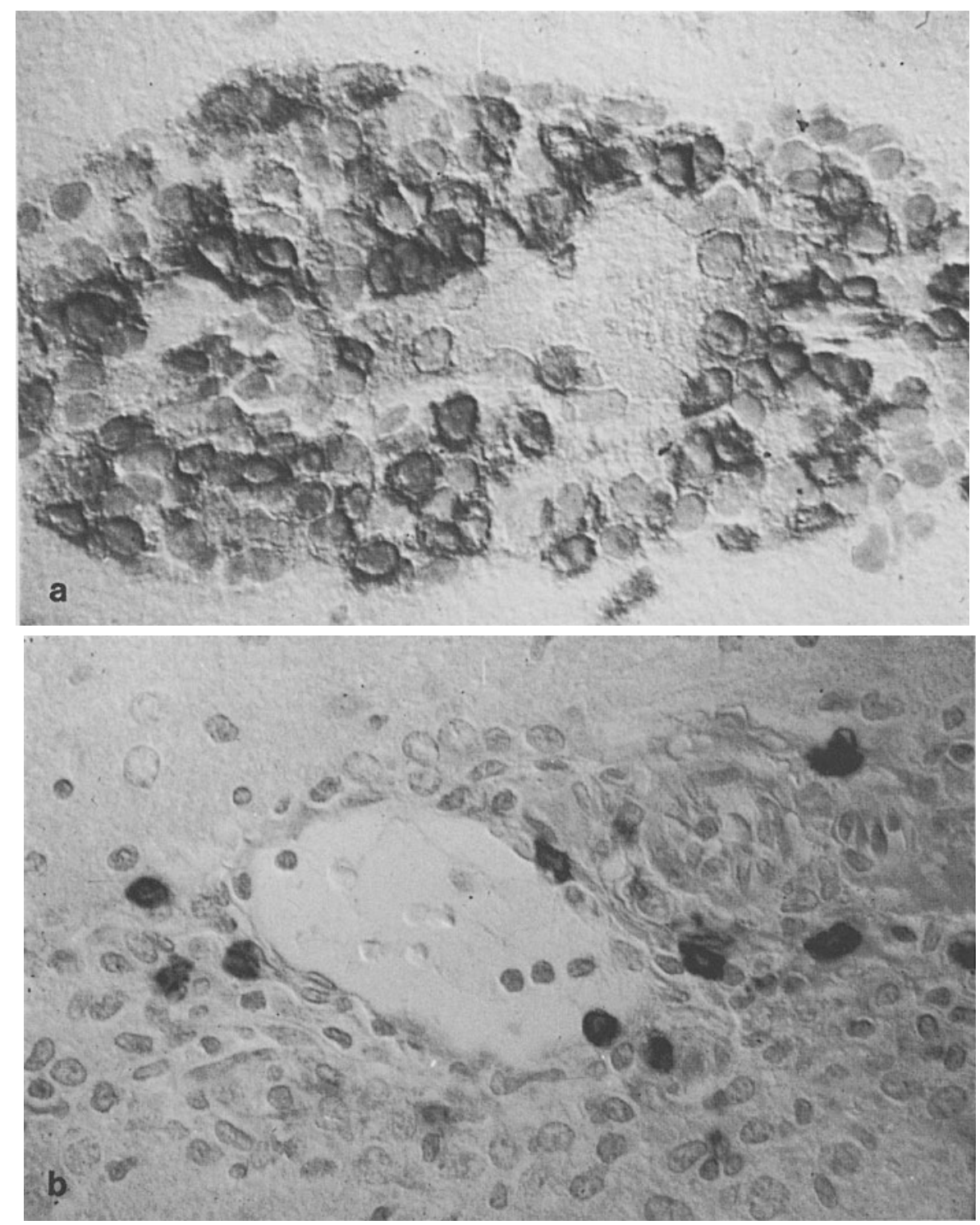

Fig. 1. Immunhistological characterization of cells in perivascular infiltrates of BDVinfected rats. Frozen sections from brains were reacted in a peroxidase anti-peroxidase reaction with a monoclonal antibody specific for $\mathrm{CD} 4+\mathrm{T}$ cells (a) or specific for CD8 $+\mathrm{T}$ cells $(\mathbf{b})$

The importance of these cells in the pathogenic mechanism has not yet been determined, especially since it has not yet been possible to demonstrate their role in antigen presentation of BDV-specific antigen in the brain. However, some evidence has accumulated that provides better insight into the mechanisms of pathogenicity and the $\mathrm{T}$ cell subsets involved. With regard to MHC class II it was shown that the elevation of the expression of this self antigen by IFN- $\gamma$ increased the proliferative 

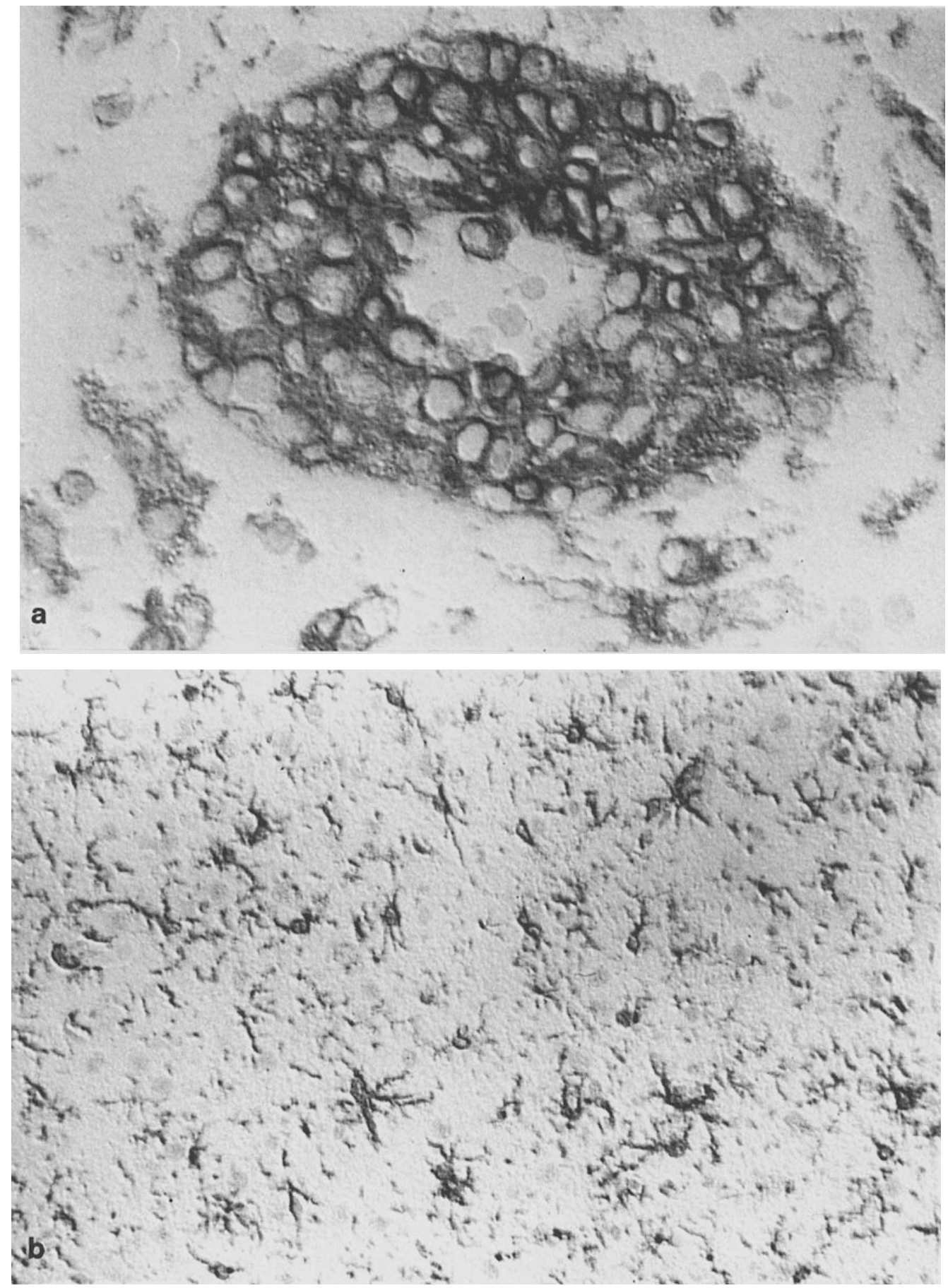

Fig. 2. Demonstration of MHC class II antigen expression in the brain of BDVinfected rats. Massive perivascular class II expression (a) and MHC class II-positive cells in the parenchyma, presumably activated microglia (b). Sections were incubated with an MHC class II-specific monoclonal antibody 

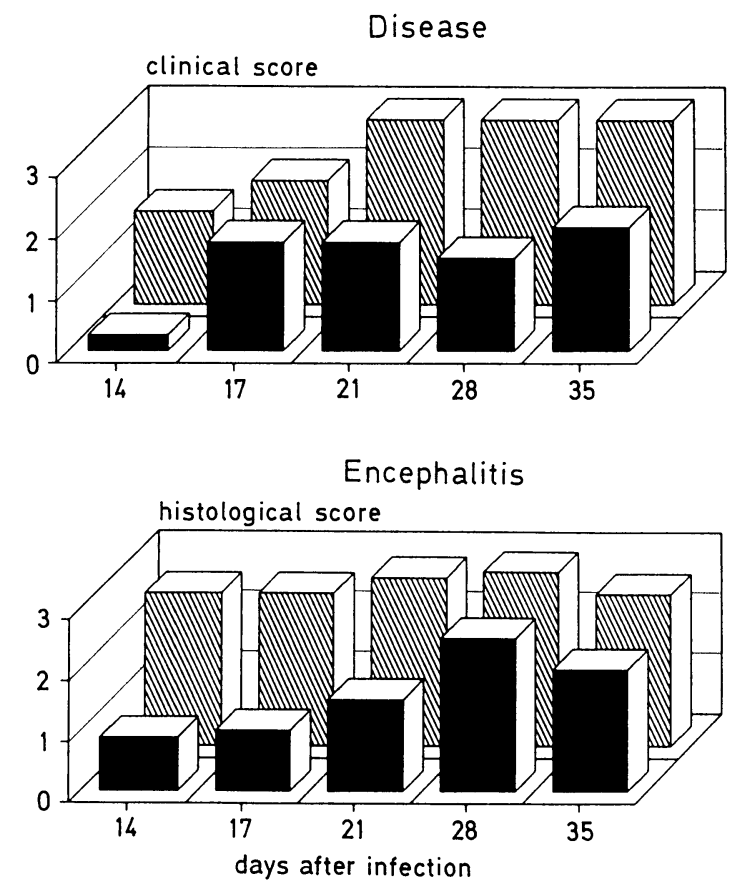

experimental group alll control

Fig. 3. Mean clinical and histological scores of BDV-infected rats treated with recombinant human transforming growth factor- $\beta 2$ (TGF- $\beta 2 ; 1 \mu \mathrm{g} /$ day i.p. 1 day before infection through day 7 after infection) and infected rats without further treatment

capacity of the BDV-specific CD4+ T cell line in vitro [29]. Likewise, the expression of MHC class II on BDV-infected astrocytes used as target cells proved to be a prerequisite for in vitro cytotoxicity by the same cell line [27].

These in vitro findings suggest that lymphokines and, obviously especially IFN- $\gamma$ and, the cells capable of producing this type of interferon might be of crucial importance in the pathogenesis of BD [32]. This assumption could be substantiated in experiments employing the transforming growth factor $\beta 2$ (TGF) in vivo [35]. TGF belongs to a class of polypeptides exhibiting diverse effects on cell growth and differentiation. These substances act as multifunctional cytokines with potent inhibitory activity on growth, differentiation and effector functions of activated $\mathrm{T}$ and $\mathrm{B}$ lymphocytes as well as macrophages [reviewed in 23 , 40]. Experiments with TGF- $\beta 2$ in BDV-infected rats revealed a reduction of the severity of clinical symptoms that was paralleled by a significant reduction of the inflammatory reaction in the brain (Fig. 3). However, the efficacy of the treatment was only transient. Immunhistological investigations revealed slightly reduced $\mathrm{CD} 4+\mathrm{T}$ cell numbers 


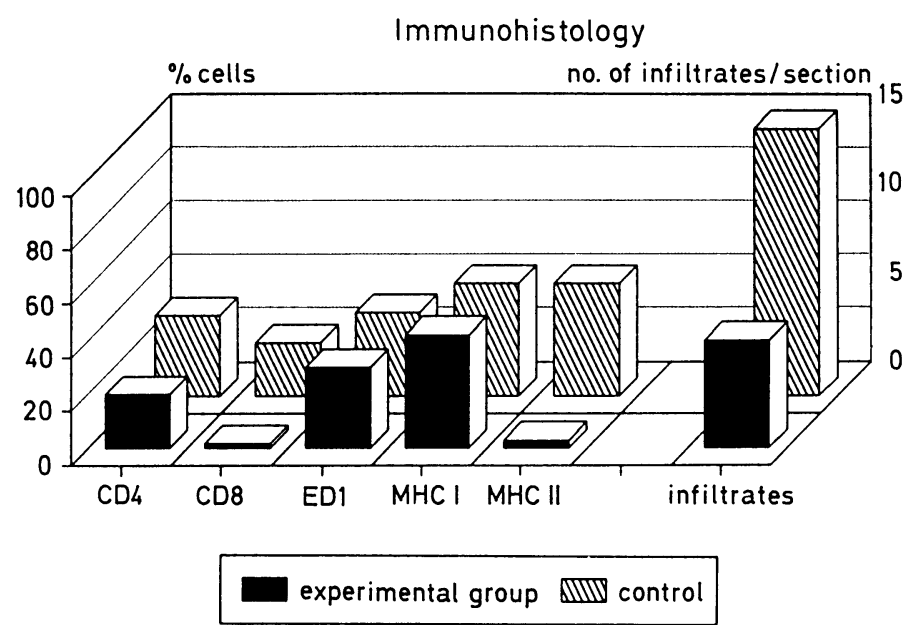

Fig. 4. Histological and immunohistological evaluation of encephalitic lesions in TGF$\beta 2$ treated and untreated BDV-infected rats. The columns on the right represent the mean number of infiltrates/section, the columns on the left show the percentage of positively immunostained cells in the infiltrates

and no changes in macrophage counts in encephalitic lesions of TGF treated rats. However, this study provided first evidence for the pathogenic importance of CD8+ $\mathrm{T}$ cells in $\mathrm{BD}$ (Fig. 4). Whereas other cell populations present in perivascular inflammatory lesions were not significantly altered, as mentioned above, CD8+ T cells were virtually absent from encephalitic lesions. Furthermore, the expression of MHC class II antigen was significantly reduced in the brain of TGF-treated Borna disease virus-infected rats, whereas MHC class I expression was not. We had shown previously that neither in the brain of infected rats [35] nor in astrocytic cultures in vitro [25, 27, 29] the virus by itself induced the expression of MHC class II, but IFN- $\gamma$ was able to do so. Since CD8 + T cells are potent producers of immune interferon and IFN$\gamma$ on its turn regulates MHC class I and class II expression, the absence of CD8 $+\mathrm{T}$ cells in the brain of TGF-treated rats might result in the observed reduction of MHC class II antigen [34]. Our recent finding that BDV-infected astrocytes produce in vitro IFN of the $\alpha / \beta$ type that shows all characteristics of a previously described astrocyte-IFN [38] agrees with this interpretation [25]. $\alpha / \beta$ IFN and, in particular, IFN produced by astrocytes upregulates MHC class I but not class II expression [11, 38] which would explain the IFN- $\gamma$ independent presence of MHC class I in TGF-treated rats. The experiments performed with TGF- $\beta$ revealed an initial drastic reduction of the local immune response after BDVinfection. The relative absence of $\mathrm{CD} 8+\mathrm{T}$ cells seemed to be decisive, since the production of soluble mediators that induce the expression 
of MHC antigen is hampered. Interestingly, and fully supporting this hypothesis, the increase of CD8+ T cells late after TGF treatment was directly correlated with an increase in the expression of MHC class II antigen in the brain and encephalitic lesions (Fig. 4). In all, the reduced expression of restriction elements for cell-mediated immune response leads to an initial inhibition of the encephalitic reaction and clinical symptoms due to a relative absence of restriction elements despite the presence of CD4+ T cells.

Additional evidence for the pathogenic importance of CD8+ T cells in $\mathrm{BD}$ comes from experiments in which BDV-infected rats were treated with monoclonal antibodies directed against various $\mathrm{T}$ cell markers [36]. Antibodies specific for CD4+ and CD8+ cells were able to decrease or even prevent the local inflammatory reaction if given early during the infection. However, CD8-specific monoclonal antibodies appeared to be much more effective and easily prevented the immunopathological disease whereas antibodies directed against CD4+ cells were significantly less effective (Table 5). These findings fully agree with the above mentioned result that $\mathrm{CD} 8+\mathrm{T}$ cells play an important role in the pathogenesis of BD insofar as cells of this phenotype have been shown to be potent producers of cytokines. We therefore proposed a sequential role of an initial $\mathrm{CD} 8+\mathrm{T}$ cell response that is decisive in triggering the local $\mathrm{CD} 4+\mathrm{T}$ cell-mediated delayed type hypersensitivity reaction in the brain after BDV infection [34, 36].

From experiments employing monoclonal antibodies directed against CD8+ cells, an explanation for another characteristic feature of Borna disease, namely brain atrophy became obvious. As mentioned before, the chronic phase of BD is characterized by a prominent cortical atrophy (Fig. 5a) and chronic debility [20]. In a recent study we could demonstrate that, in addition to the inhibition of the immunopathological reaction, treatment of $\mathrm{BDV}$-infected rats with anti-CD8 monoclonal antibodies resulted only in minimal brain-cell lesions and no obvious loss of brain substance could be seen even long after infection (Fig. 5b) [2]. In untreated rats necrobiotic changes of brain cells were found to be present from early stages of the disease and neuronal cell loss was one of the most prominent features of BD. By characterizing the brain cells that express MHC class I antigen it became evident that this self antigen could be demonstrated on neurons and astrocytes [2, 25]. The most intriguing finding upon histology was the coincidence of the occurrence of CD8+ cells and a dramatic increase of MHC class I on the one hand, and the presence of first neuronal degenerations on the other. In rats depleted of CD8 + T cells in vivo, no marked amounts of MHC class I antigen was detected in the brain parenchyma, whereas MHC class II expression was not different in any of the BDV-infected rats, regardless 
L. Stitz et al.

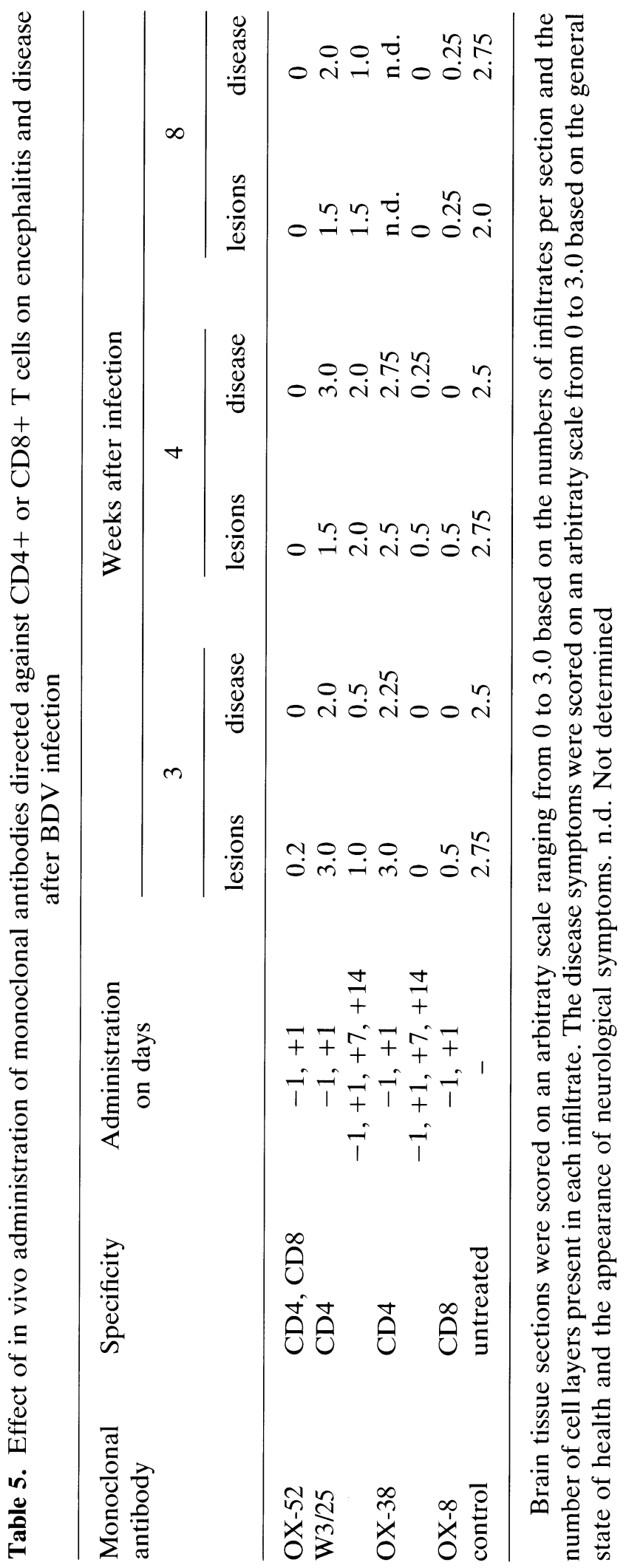



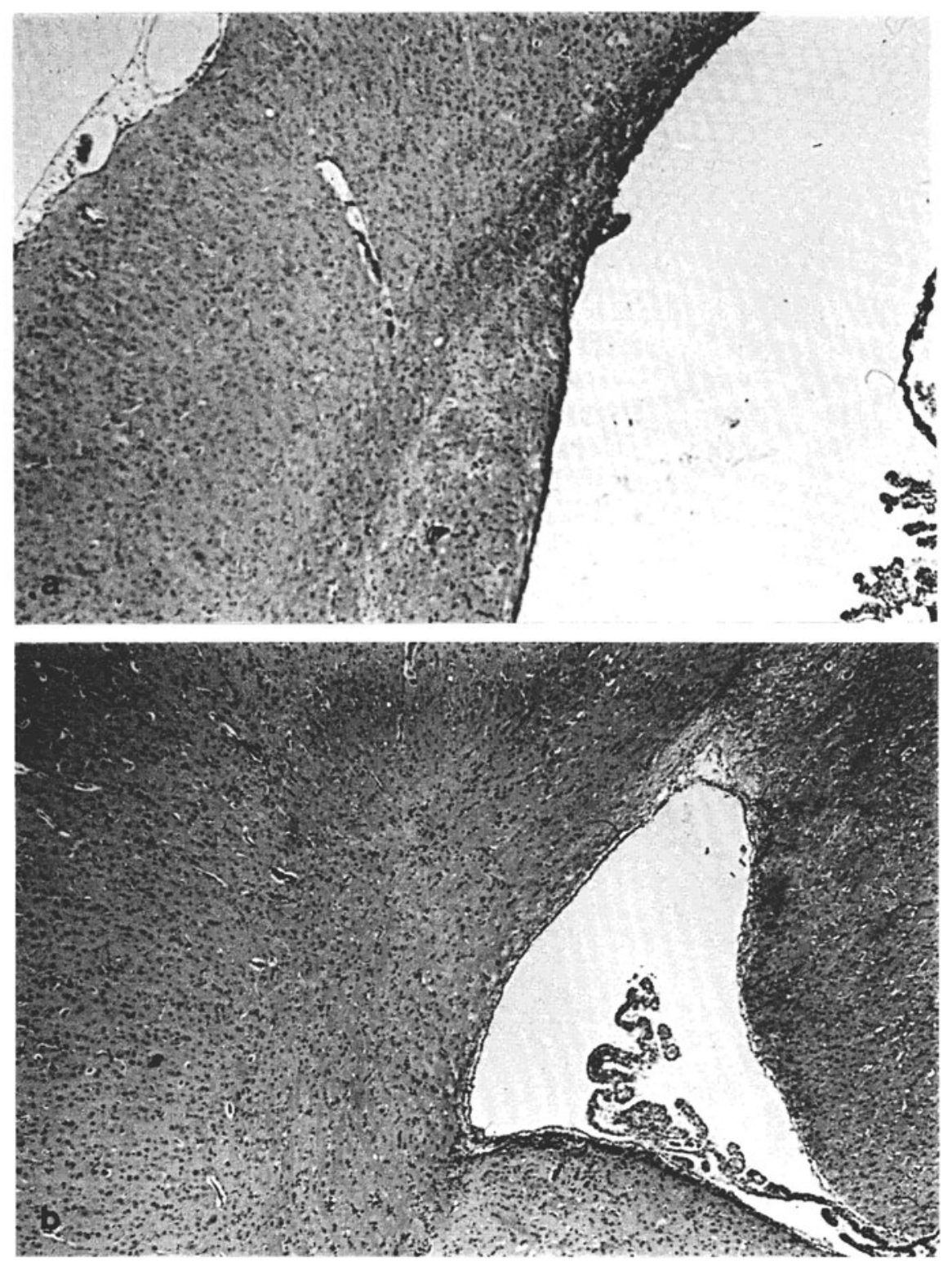

Fig. 5. Severe cortical brain atrophy in an adult untreated rat 8 weeks after BDV infection. Note the "burned-out" inflammation and the enormously dilatated ventricle (a). Brain section of a BDV-infected rat treated with a monoclonal directed against CD8 $+\mathrm{T}$ cells. Note the complete lack of atrophy or signs of inflammation (b)

of whether treated with anti-T cell antibodies or not. Since coexpression of MHC class I antigen in association with virus-specific proteins renders cells as targets for cytotoxic CD8 + T lymphocytes [reviewed in 42], we consequently looked for cytotoxic $\mathrm{T}$ cell activity in BDV-infected rats. Employing syngeneic and allogeneic BDV-infected target cells we could demonstrate virus-specific cytotoxic $T$ cell activity (Table 6) [25]. 
Table 6. Cytotoxic activity in lymphocyte preparation isolated from the brain of BDVinfected rats

\begin{tabular}{lc}
\hline Type of target cell & \% Lysis of target cell \\
\hline Syngeneic BDV-infected & 45 \\
Syngeneic uninfected & 3 \\
Allogeneic BDV-infected & 5 \\
Syngeneic BDV-infected & 40 \\
Syngeneic uninfected & 5 \\
Syngeneic BDV-infected in the presence of Anti-MHC & \\
class I antibody & 7 \\
\hline
\end{tabular}

Lymphocytes from the brain were isolated on a modified RPMI/Ficoll gradient [25]. Specific lysis was determined after a $9 \mathrm{~h}$ coincubation of effector cells with ${ }^{51} \mathrm{Cr}$ labeled tariget cells. Effector: target ratio 30:1

Blocking experiments using antibodies directed against MHC class I antigen provided further evidence for the presence and activity of classical cytotoxic $\mathrm{T}$ lymphocytes in the brain of BDV-infected rats (Table 6).

\section{Conclusion}

In this short review we have summarized the present knowledge of the pathogenesis of Borna disease and presented data that help describe the cellular basis of this immunopathological disease of the brain. From all of our work it becomes apparent that interactions and the interplay among the components of the cellular immune response and between the cellular immune system and lymphokines are of crucial importance. As exemplified by immunosuppression and immunomodulation with various drugs, understanding of the pathogenetic pathways is the inevitable prerequisite to possible interference with disease processes. Here, we also show that Borna disease is not only a useful model of a virusinduced immunological disease but we have also provided evidence that the experimental disease in rats presently possibly represents the best model for studying in vivo cytotoxicity exerted by classical CD8+ cytotoxic T lymphocytes.

\section{Acknowledgement}

The studies mentioned here were performed partially in cooperation with $\mathrm{H}$. Becht, $\mathrm{S}$. Herzog, K. Frese, O. Narayan, O. Planz and M. Sobbe. We thank B. Boschek for 
critically reading the manuscript. L. Stitz is a recipient of a Hermann- and LillySchilling Professorship for Theoretical and Clinical Medicine.

\section{References}

1. Bilzer T, Planz O, Stitz L, Lipkin WI (1993) Tropism of Borna disease virus. I. Distribution of virus specific nucleic acid and antigen in the nervous system of adult rats. Submitted for publication

2. Bilzer T, Stitz L (1993) Brain cell lesions in Borna disease are mediated by $T$ cells. In: Kaaden OR, Eichhorn W, Czerny CP (eds) Unconventional agents and unclassified viruses. Springer, Wien New York, pp 153-158 (Arch Virol [Suppl] 7)

3. Briese T, De la Torre JC, Lewis A, Ludwig H, Lipkin WI (1992) Borna disease virus, a negative-strand RNA virus, transcribes in the nucleus of infected cells. Proc Natl Acad Sci USA 89: 11486-11489

4. Carbone KM, Duchala CS, Griffin JW, Kincaid AL, Narayan O (1987) Pathogenesis of Borna disease in rats: Evidence that intra-axonal spread is the major route for virus dissemination and the determinant for disease incubation. $\mathbf{J}$ Virol 61: $3431-3440$

5. Carbone KM, Trapp BD, Griffin JW, Duchala CS, Narayan O (1989) Astrocytes and Schwann cells are virus-host cells in the nervous system of rats with Borna disease. J Neuropathol Exp Neurol 48: 631-644

6. Cole GA, Nathanson N, Prendergast RA (1972) Requirement for theta-bearing cells in lymphocytic choriomeningitis virus-induced central nervous system disease. Nature 238: $335-337$

7. De la Torre JC, Carbone KM, Lipkin WI (1990) Molecular characterisation of Borna disease agent. Virology 179: 853-856

8. Deschl U, Stitz L, Herzog S, Frese K, Rott R (1990) Determination of immune cells and expression of major histocompatibility complex class II antigen in encephalitic lesions of experimental Borna disease. Acta Neuropathol 81: 41-50

9. Dittrich W, Bode L, Ludwig H, Kao M, Schneider K (1989) Learning deficiencies in Borna disease virus-infected but clinically healthy rats. Biol Psychiatry 26: $818-828$

10. Doherty PC, Zinkernagel RM (1974) T cell-mediated immunopathology in viral infections. Transplant Rev 19: 89-120

11. Halloran PF, Urmson J, van der Meide PH, Autenried P (1989) Regulation of MHC expression in vivo: II. IFN-alpha/beta inducers and recombinant IFN-alpha modulate MHC antigen expression in mouse tissues. J Immunol 142: 4241-4247

12. Herzog S, Rott R (1980) Replication of Borna disease virus in cell culture. Med Microbiol Immunol 168: 153-158

13. Herzog S, Wonigeit K, Frese K, Hedrich HJ, Rott R (1985) Effect of Borna disease virus infection in athymic rats. J Gen Virol 66: 503-508

14. Hirano N, Kao M, Ludwig H (1983) Persistent, tolerant or subacute infection in Borna disease virus infected rats. J Gen Virol 64: 1521-1530

15. Lipkin WI, Travis KM, Carbone KM, Wilson CM (1990) Isolation and characterisation of Borna disease agent cDNA clones. Proc Natl Acad Sci USA 87: $4184-4188$

16. Ludwig H, Bode L, Gosztonyi G (1988) Borna disease. A persistent virus infection of the central nervous system. Progr Med Virol 35: 107-151 
17. McClure MA, Thibault KJ, Hatalski CG, Lipkin WI (1992) Sequence similarity between Borna disease virus p40 and a duplicated domain within the paramyxoand rhabdovirus polymerase proteins. J Virol 66: 6572-6577

18. Meulen ter V, Stephenson JR (1983) The possible role of viral infections in MS and other related demyelinating diseases. In: Hallpike JF, Adams CWM, Tourtellotte WW (eds) Multiple Sclerosis. Chapmann and Hall, London, pp 241-274

19. Nagashima K, Wege H, Meyermann R, Ter Meulen V (1978) Corona virus induced subacute demyelinating encephalomyelitis in rats: a morphological analysis. Acta Neuropathol 44: 63-70

20. Narayan O, Herzog S, Frese K, Scheefers K, Rott R (1983) Behavioral disease in rats caused by immunopathological response to persistent Borna disease virus in the brain. Science 220: 1401-1403

21. Narayan O, Herzog S, Frese K, Scheefers K, Rott R (1983) Pathogenesis of Borna disease in rats: Immune-mediated viral ophthalmoencephalopathy causing blindness and behavioral abnormalities. J Infect Dis 148: 305-315

22. Padgett BL, Walter DL, zuRhein GM, Ederoode RJ, Dessel BH (1971) Cultivation of papova-like virus from human brain with progressive multifocal leukoencephalopathy. Lancet i: 1257-1260

23. Palladino MA, Morris RE, Starnes HF, Levinson DA (1990) The transforming growth factor-betas: A new family of immunoregulatory molecules. Ann NY Acad Sci 593: $181-185$

24. Planz O, Bilzer T, Lipkin WI, Stitz L (1993) Tropism of Borna disease virus. II. Presence of Borna disease virus in non-neural tissue of immunosuppressed and newborn-infected rats. Submitted for publication

25. Planz O, Bilzer T, Sobbe M, Stitz L (1993) Lysis of MHC class I-bearing cells in Borna disease virus-induced degenerative encephalopathy. J Exp Med 178: $163-174$

26. Price RW, Brew BJ (1988) The AIDS dementia complex. J Infect Dis 158: 1079-1083

27. Richt JA, Stitz L (1992) Borna disease virus infected astrocytes function in vitro as antigen- presenting and target cells for virus-specific CD4-bearing lymphocytes. Arch Virol 124: 95-109

28. Richt JA, Stitz L, Deschl U, Frese K, Rott R (1990) Borna disease virus-induced meningoencephalomyelitis caused by a virus-specific CD4+ T-cell mediated immune reaction. J Gen Virol 71: 2565-2573

29. Richt JA, Stitz L, Wekerle H, Rott R (1989) Borna disease, a progressive meningoencephalomyelitis as a model for CD4+ T cell-mediated immunopathology in the brain. J Exp Med 170: 1045-1050

30. Richt JA, VanDeWoude S, Zink MC, Narayan O, Clements JE (1991) Analysis of Borna disease virus-specific RNA's in infected cells and cultures. J Gen Virol 72: 2251-2255

31. Rott R, Herzog S, Bechter K, Frese K (1991) Borna disease, a possible hazard for man? Arch Virol 118: 143-149

32. Shankar V, Kao M, Hamir AN, Sheng H, Koprowski H, Dietzschold B (1992) Kinetics of virus spread and change in levels of several cytokine mRNAs in the brain after intranasal infection of rats with Borna disease virus. J Virol 66: 992-998

33. Stephenson JR, Ter Meulen V (1979) Subacute sclerosing panencephalitis: characterization of the etiological agent and its relationshio to morbilli virus. In: Tyrell DAJ (ed) Aspects of slow and persistent virus infection. Martinus Nijhoff, The Hague/Boston/London, pp 61-75 
34. Stitz L, Planz O, Bilzer T, Frei K, Fontana A (1991) Transforming growth factor $\beta$ modulates $\mathrm{T}$ cell-mediated encephalitis caused by Borna disease virus. Pathogenic importance of CD8+ cells and suppression of antibody formation. J Immunol 147: $3581-3586$

35. Stitz L, Schilken D, Frese K (1991) Atypical dissemination of the highly neurotropic Borna disease virus during persistent infection in cyclosporine A-treated, immunosuppressed rats. J Virol 65: 457-460

36. Stitz L, Sobbe M, Bilzer T (1992) Preventive effects of early anti-CD4 or anti-CD8 treatment on Borna disease in rats. J Virol 66: 3316-3323

37. Stitz L, Soeder D, Deschl U, Frese K, Rott R (1989) Inhibition of immunemediated meningoencephalitis in persistently Borna disease virus infected rats by Cyclosporine A. J Immunol 143: 4250-4256

38. Tedeschi B, Barrett JN, Keane RW (1986) Astrocytes produce interferon that enhances the expression of $\mathrm{H}-2$ antigens on a subpopulation of brain cells. J Cell Biol 102: 2244-2253

39. VanDeWoude S, Richt JA, Zink MC, Rott R, Narayan O, Clements JE (1990) A Borna virus cDNA encoding a protein recognized by antibodies in humans with behavioral disease. Science 250: 1278-1281

40. Wahl SM, McCartney-Francis N, Mergenhagen SE (1989) Inflammatory and immunoregulatory role of TGF- $\beta$. Immunol Today 10: 258-262

41. Weimer LP, Herdon RM, Narayan O, Johnson RT (1972) Further studies of simian virus-40-like virus isolated from human brain. J Virol 10: 147-152

42. Zinkernagel RM, Doherty PC (1979) MHC-restricted cytotoxic T cells: Studies on the biological role of polymorphic major transplantation antigens determining $\mathrm{T}$ cell restriction-specificity, function and responsiveness. Adv Immunol 27: 52-142

Authors' address: Dr. L. Stitz, Institut fūr Virologie, Justus-Liebig-Universität, Frankfurterstrasse 107, D-35392 Gießen, Federal Republic of Germany. 